\title{
Four-year observation of predictability and stability of small incision lenticule extraction
}

\author{
Tian Han ${ }^{1+}$, Ke Zheng ${ }^{1+}$, Yingjun Chen ${ }^{1}$, Yang $\mathrm{Gao}^{2}, \mathrm{Li} \mathrm{He}^{3}$ and Xingtao Zhou ${ }^{1 *}$ [D
}

\begin{abstract}
Background: To investigate long-term refractive outcomes, wavefront aberrations and quality of life after small incision lenticule extraction (SMILE) for moderate to high myopia.

Methods: A total of 26 patients (47 eyes) with preoperative mean spherical equivalent (SE) of $-6.30 \pm 1.47$ diopters (D) who underwent SMILE were recruited. The measurements included uncorrected distance visual acuity (UDVA), corrected distance visual acuity (CDVA), manifest refraction, wavefront aberrations, and quality of life.

Results: At 4 years postoperatively, UDVA was better than or equal to 20/20 in $92 \%$ of eyes. The efficacy index was $1.07 \pm 0.16 .89 \%$ of eyes were within $\pm 0.5 \mathrm{D}$ of the intended refractive target. No eye lost any Snellen lines. The safety index was $1.16 \pm 0.14$. No significant changes of SE occurred among postoperative follow-ups at months 1, 3, 6 and years 1, 2, 4 ( $P>0.05$, Scheffe test). Higher-order aberrations, coma, spherical aberration and higher-order astigmatism increased postoperatively, and no significant changes of aberrations were detected among the 1-month, 6-month or 4-year follow-ups postoperatively (37 eyes). Compared to the spectacles group, the surgery group showed a significantly higher total score on quality of life (45.71 \pm 2.61 vs $39.96 \pm 3.56$, $P<0.001)$.

Conclusions: SMILE provides a predictable and stable correction of moderate to high myopia as documented by long-term follow-up.

Keywords: Small incision lenticule extraction (SMILE), Aberrations, Quality of life, Quality of Life Impact of Refractive Correction (QIRC) questionnaire

Abbreviations: ANOVA, Analysis of variance; CDVA, Corrected distance visual acuity; D, Diopters; HOAs, Higher-order aberrations; IQR, Interquartile range; LASIK, Laser in situ keratomileusis; PRK, Photorefractive keratectomy; QIRC, Quality of life impact of refractive correction; RMS, Root mean square; SE, Spherical equivalent; SMILE, Small incision lenticule extraction; SPSS, Statistical package for social sciences; UDVA, Uncorrected distance visual acuity
\end{abstract}

\section{Background}

Small incision lenticule extraction (SMILE) was first introduced by Shah and Sekundo in 2011 [1, 2]. Compared to laser in situ keratomileusis (LASIK), SMILE is a minimally invasive and flap-less procedure. Promising clinical results have been reported [3-14]. Only a few articles on the long-term refractive outcomes after SMILE have been

\footnotetext{
* Correspondence: doctzhouxingtao@163.com

${ }^{\dagger}$ Equal contributors

${ }^{1}$ Department of Ophthalmology and Vision Science, Eye and ENT Hospital of

Fudan University, No.19 Baoqing RoadXuhui District, Shanghai, China

Full list of author information is available at the end of the article
}

reported $[13,15]$. Scientific evidence documenting SMILE over long-term follow-up is necessary to gain more support and wider acceptance of the procedure [16]. The aim of this study is to investigate four-year visual quality (refractive outcomes and aberrations) and quality of life outcomes after the SMILE procedure.

\section{Methods \\ Subjects}

Patients who underwent SMILE at the Refractive Surgery Center of the Department of Ophthalmology, Eye and ENT Hospital of Fudan University between January, 2011 
and May, 2012 were enrolled in the prospective study. Inclusion criteria included age over 18 years, sphere of $-3.00--9.00$ diopters (D) with astigmatism up to $-2.00 \mathrm{D}$, corrected distance visual acuity (CDVA) of $20 / 20$ or better, stable refraction for 2 years, and no use of any kind of contact lenses within the previous 2 weeks. Patients with systemic diseases, a history of ocular surgery or trauma, or a history of ocular disease other than myopia or astigmatism were excluded. Among these myopia patients, those who received SMILE for both eyes were recruited in the quality-oflife study. Patients over 39 years of age were excluded as requisition of the Quality of Life Impact of Refractive Correction (QIRC) questionnaire [17].A group of individuals who wore spectacles full-time were enrolled as a control. Inclusion criteria included age 18-39 years, CDVA of 20/20 or better, sphere of $-3.00--9.00$ D with astigmatism up to $-2.00 \mathrm{D}$, stable refraction for 2 years, use of spectacles for more than 4 years, and no other ophthalmic problems.

This study followed the tenets of the Declaration of Helsinki and was approved by the ethics committee of the Eye and ENT Hospital of Fudan University. Informed written consent was obtained from all participants.

\section{Procedures}

The same surgeon (XTZ) performed all the SMILE procedures. The VisuMax femtosecond laser system (Carl Zeiss Meditec, Jena, Germany) was used with a repetition rate of $500 \mathrm{kHz}$ and pulse energy of 130 $\mathrm{nJ}$. The lenticule diameter was set at $6.5-6.7 \mathrm{~mm}$ and the stromal cap was completed at a $100-\mu \mathrm{m}$ depth with a diameter of $7.5 \mathrm{~mm}$. A 90-degree single side cut with a length of $2.0-4.0 \mathrm{~mm}$ was created during the procedure. After surgery, topical levofloxacin, $0.1 \%$ fluorometholone solution, and non-preserved artificial tears (carboxymethylcellulose sodium eye drops; Allergan, Inc., Irvine, CA) were used.

\section{Measurements}

The outcome measures included uncorrected distance visual acuity (UDVA), CDVA, manifest refraction, and wavefront aberrations. Routine examinations, like slitlamp examination, rotating Scheimpflug camera imaging (Pentacam, Oculus $\mathrm{GmbH}$ ), were also preformed.

Postoperative time points included 1, 3, 6 months and 1, 2, 4 years postoperatively.

Wavefront aberrations were measured with a HartmannShack WASCA aberrometer (Carl Zeiss Meditec AG) with a $6.0 \mathrm{~mm}$ pupil using sixth order Zernike polynomials. The

Table 1 Refractive outcomes during the follow-up period

\begin{tabular}{|c|c|c|c|c|c|}
\hline Variables & Preoperative & 6 Months postoperative & 4 Years postoperative & P (Preop to 4 years postop) & P (6 Months to 4 years postop) \\
\hline \multicolumn{6}{|l|}{ LogMAR UDVA } \\
\hline Mean $\pm S D$ & & $-0.05 \pm 0.06$ & $-0.04 \pm 0.06$ & - & 0.094 \\
\hline Medium(IQR) & - & $-0.08(-0.08$ to 0$)$ & $-0.08(-0.08$ to 0$)$ & & \\
\hline \multicolumn{6}{|l|}{ LogMAR CDVA } \\
\hline Mean & $-0.01 \pm 0.03$ & $-0.08 \pm 0.06$ & $-0.08 \pm 0.06$ & $<0.001$ & 0.570 \\
\hline Medium(IQR) & $O(0$ to 0$)$ & $-0.08(-0.08$ to -0.08$)$ & $-0.08(-0.08$ to -0.08$)$ & & \\
\hline \multicolumn{6}{|l|}{ Sphere (D) } \\
\hline Mean \pm SD & $-5.94 \pm 1.45$ & $0.14 \pm 0.35$ & $0.05 \pm 0.41$ & $<0.001$ & 0.278 \\
\hline Range & -8.50 to -3.25 & -0.50 to 1.25 & -1.00 to 1.25 & & \\
\hline \multicolumn{6}{|l|}{ Cylinder (D) } \\
\hline Mean \pm SD & $-0.73 \pm 0.49$ & $-0.29 \pm 0.27$ & $-0.28 \pm 0.29$ & $<0.001$ & 0.747 \\
\hline Medium(IQR) & $-0.50(-1.00$ to 0$)$ & $-0.25(-0.50$ to 0$)$ & $-0.25(-0.50$ to 0$)$ & & \\
\hline \multicolumn{6}{|l|}{ SE } \\
\hline Mean \pm SD & $-6.30 \pm 1.47$ & $-0.01 \pm 0.33$ & $-0.09 \pm 0.39$ & $<0.001$ & 0.929 \\
\hline Range & -8.75 to -3.50 & -0.75 to 0.88 & -1.00 to 0.88 & & \\
\hline \multicolumn{6}{|l|}{ The efficacy index } \\
\hline Mean \pm SD & - & $1.11 \pm 0.17$ & $1.07 \pm 0.16$ & - & 0.275 \\
\hline Medium(IQR) & & $1.0(1.0$ to 1.2$)$ & $1.0(1.0$ to 1.2$)$ & & \\
\hline \multicolumn{6}{|l|}{ The safety index } \\
\hline Mean $\pm S D$ & - & $1.17 \pm 0.15$ & $1.16 \pm 0.14$ & - & 0.622 \\
\hline Medium(IQR) & - & $1.2(1.0$ to 1.2$)$ & $1.2(1.0$ to 1.2$)$ & & \\
\hline
\end{tabular}

Preop preoperative, Postop postoperative, UDVA uncorrected distance visual acuity, IQR interquartile range, CDVA corrected distance visual acuity, D diopters, SE spherical equivalent 

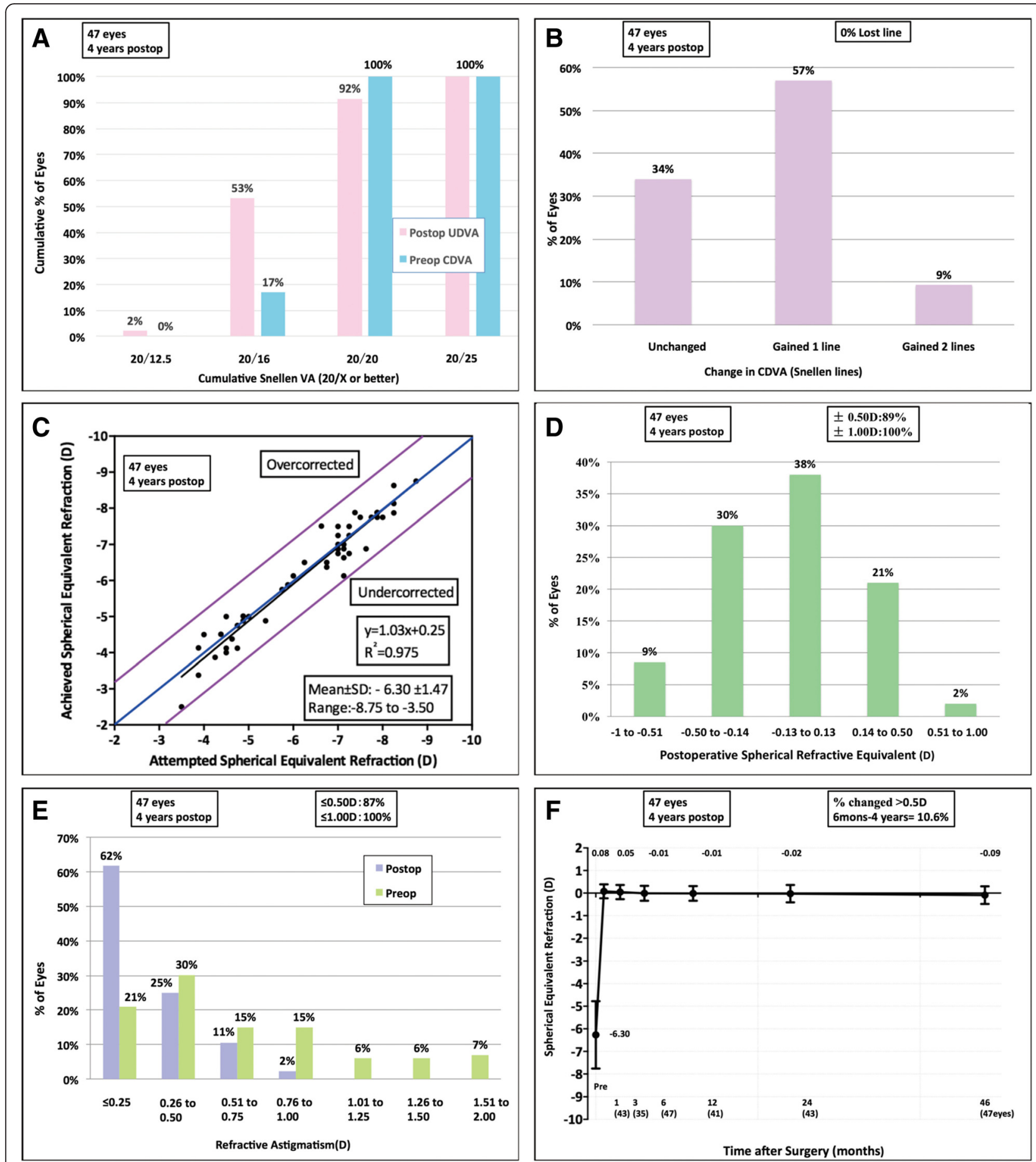

Fig. 1 Refractive outcomes at 4 years postoperatively for 47 eyes with moderate to high myopia treated with SMILE. UDVA = uncorrected distance visual acuity; CDVA = corrected distance visual acuity; $D=$ diopters; Postop = postoperative; Preop = preoperative

root mean square (RMS) of higher-order aberrations (HOAs), spherical aberration, coma, higher-order astigmatism, trefoil and tetrafoil was calculated. Only measurements in eyes with a pupil of $6.0 \mathrm{~mm}$ or larger were included. Thus, the aberration measurements of thirty- seven eyes for 1, 6 months and 4 years postoperatively were collected.

The Chinese version of the QIRC questionnaire was completed by Xu Congyi et al. [18] and showed favorable repeatability and validity. The QIRC questionnaire 
Table 2 Time course of aberrations after SMILE

\begin{tabular}{|c|c|c|c|c|c|}
\hline Variables & Preoperative & 1 Month postoperative & 6 Months postoperative & 4 Years postoperative & $P$ \\
\hline $\mathrm{HOAs}(\mu \mathrm{m})$ & $0.31 \pm 0.12$ & $0.48 \pm 0.16$ & $0.53 \pm 0.17$ & $0.51 \pm 0.11$ & $<0.001$ \\
\hline Spherical aberration ( $\mu \mathrm{m})$ & $0.07 \pm 0.15$ & $0.15 \pm 0.13$ & $0.17 \pm 0.14$ & $0.18 \pm 0.14$ & 0.003 \\
\hline Coma $(\mu m)$ & $0.18 \pm 0.13$ & $0.36 \pm 0.23$ & $0.40 \pm 0.23$ & $0.40 \pm 0.15$ & $<0.001$ \\
\hline Higher-order astigmatism ( $\mu \mathrm{m})$ & $0.05 \pm 0.03$ & $0.09 \pm 0.06$ & $0.09 \pm 0.05$ & $0.10 \pm 0.06$ & 0.001 \\
\hline Trefoil $(\mu m)$ & $0.14 \pm 0.08$ & $0.16 \pm 0.08$ & $0.16 \pm 0.08$ & $0.16 \pm 0.09$ & 0.693 \\
\hline Tetrafoil ( $\mu \mathrm{m})$ & $0.06 \pm 0.03$ & $0.08 \pm 0.05$ & $0.08 \pm 0.04$ & $0.08 \pm 0.06$ & 0.29 \\
\hline
\end{tabular}

HOAs higher-order aberrations

was used to assess the quality of life of the spectacles group and the surgery group at the last follow-up.

\section{Data analysis}

All statistical analysis was performed using the Statistical Package for Social Sciences (SPSS, Version 20) (IBM, Armonk, NY, USA). The Kolmogorov-Smirnov test was used to test for normality. Non-normally distributed data were described as the mean, medium, and interquartile range (IQR). One-way analysis of variance (ANOVA) was used for the analysis of changes during the time course, with Tukey test and Scheffe test for multiple comparisons. When variables could not meet the condition of ANOVA, the Wilcoxon signed-rank test was used for paired data and the Mann-Whitney U test was used for unpaired data. For proportions, Fisher's exact test was used. For all tests, a $P<0.05$ was defined as statistically significant.

\section{Results}

The preoperative mean age of the patients was $29.02 \pm$ 7.23 years (range: 19-44 years) and mean spherical equivalent (SE) was $-6.30 \pm 1.47 \mathrm{D}$ (range: $-3.50--8.75$ D). The follow-up was $46.43 \pm 2.33$ months (range: $43-$ 58 months). None of the 47 eyes showed signs of ectasia.

\section{Refractive outcomes}

Refractive outcomes pre-operatively and at postoperative follow-ups at 6 months and 4 years are summarized in Table 1 and Fig. 1. At the 4-year follow-up, UDVA was better than or equal to $20 / 20$ in $92 \%$ of eyes and $20 / 16$ in $53 \%$. The efficacy index was $1.07 \pm 0.16$. $89 \%$ of eyes were within $\pm 0.5 \mathrm{D}$ of the intended refractive target. No significant changes of SE occurred among postoperative follow-ups at months $1,3,6$ and years 1 , 2, $4 \quad(P>0.05$, Scheffe test). No eye lost any Snellen lines and $9 \%$ showed an increase of 2 lines. The safety index was $1.16 \pm 0.14$.

\section{Wavefront aberrations}

Aberrations outcomes are summarized in Table 2. HOAs, coma, and higher-order astigmatism increased since 1 month postoperatively (Tukey test, $P<0.01$ ). Moreover, significant differences of spherical aberration were found between preoperative values and values at 6 months, 4 years postoperatively (Tukey test, $P<0.05$ ). Among these aberrations, postoperative coma showed the greatest increase after the surgery (Fig. 2). No significant differences of HOAs, spherical aberration, coma, higher-order astigmatism, trefoil and tetrafoil were detected among the 1-month, 6-month or 4-year followups postoperatively (Tukey test, $P>0.05$ ).

\section{Quality of life evaluation}

No significant difference in characteristics was found between the surgery group and the spectacle group (Table 3). There are 19 subjects in the surgery group and 54 in the spectacle group, respectively. Compared to the spectacles group, the surgery group showed a significantly higher score in total score $(45.71 \pm 2.61$ vs $39.96 \pm 3.56, P<0.001)$, the visual function, 4 of 5 convenience issues, both of the economic concerns, and 1 of 7 well-being measurements (Table 4). There were no significant differences between responses regarding

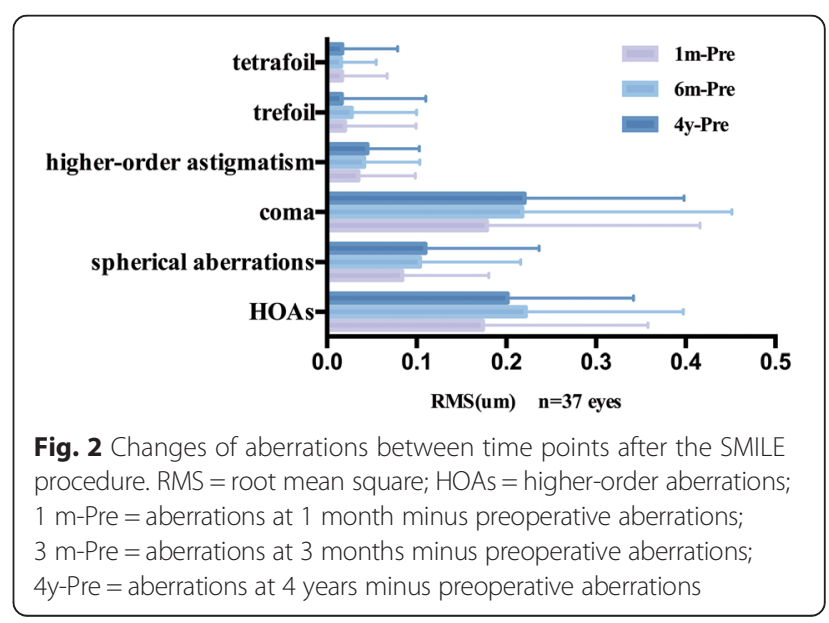


Table $\mathbf{3}$ Characteristics of the surgery and spectacles groups

\begin{tabular}{llll}
\hline Characteristics & Surgery group & Spectacles group & $P$ \\
\hline Sample Size $(n)$ & 19 & 54 & - \\
Sex (M/F) & $6 / 13$ & $24 / 30$ & $30.04 \pm 4.76$ \\
Age & $31.16 \pm 5.39$ & $22 / 32$ & 0.241 \\
Myopia level (the worse eye, SE: -3.00 to -6.00D/<-6.00D) & $6 / 13$ & $51 / 3$ & 0.336 \\
Are you satisfied with your vision? (satisfied/unsatisfied) & $19 / 0$ & $28 / 26$ & 0.399 \\
How would you characterize your health? (good/excellent) & $10 / 9$ & $54 / 0$ \\
CDVA for the worse eye $\geq 20 / 20$ & $19 / 0$ & & -583 \\
\hline
\end{tabular}

$D$ diopters, SE spherical equivalent, CDVA corrected distance visual acuity

symptoms, 1 of 5 convenience concerns, any of 4 health concerns, or 6 of 7 well-being measurements.

\section{Discussion}

SMILE has proven to be an effective, predictable and safe procedure since Shah and Sekundo first introduced it five years ago [3-12]. In this study, we report the long-term observation of visual quality (refractive outcomes and aberrations) and quality of life outcomes in SMILE patients up to 58 months.

In this study, UDVA was better than or equal to $20 / 20$ in $92 \%$ of eyes and 20/16 in $53 \%$. No eye lost any line of CDVA and $9 \%$ showed an increase of 2 lines. The efficacy and safety index were $1.07 \pm 0.16$ and $1.16 \pm$ 0.14 , respectively. Pedersen et al. showed $72 \%$ eyes with 20/20 or better UDVA in 57 eyes of high myopia targeted for emmetropia at 3 years after SMILE procedure [15]. The discrepancy of UDVA results might due to the different study subjects. Pedersen et al. showed the refractive outcomes of patients with high myopia (92\% of eyes more than $-6.00 \mathrm{D}$ ), while in this study, we studied the outcomes after SMILE for moderate to high myopia (59\% of eyes more than $-6.00 \mathrm{D})$. Kim et al. [3] observed that at 12 months postoperatively, $93.1 \%$ of the eyes in the mild- to moderate-myopia group and $76.8 \%$ of eyes in high myopia group had UDVA of 20/ 20 or better $(P<0.05)$. Blum et al. showed the efficacy index and safety index of the worldwide first 41 eyes treated using SMILE at the 5-year follow-up was 0.9 and 1.2, respectively [13]. They performed SMILE with the old type VisuMax at a repetition rate of $200 \mathrm{kHz}$ with a typical pulse energy $<300 \mathrm{~nJ}$, while we used the new type VisuMax at a repetition rate of $500 \mathrm{kHz}$. A $500 \mathrm{kHz}$ VisuMax caused less tissue damage and resulted in better outcomes. These results indicate the favorable efficacy and safety of the SMILE procedure.

Considering long-term predictability and stability, $89 \%$ of eyes were within $0.5 \mathrm{D}$ and $100 \%$ were within $1.0 \mathrm{D}$ of the intended refractive target. In the study by Pedersen IB et al., these values were $78 \%$ and $90 \%$ respectively [15]. Blum et al. observed that $48.2 \%$ of eyes were within $0.5 \mathrm{D}$ and $78.6 \%$ were within $1.0 \mathrm{D}$
[13]. In our study, no significant changes in SE occurred between postoperative follow-ups, although $\mathrm{SE}$ was decreased from $-0.01 \pm 0.33 \mathrm{D}$ at 6 months to $-0.09 \pm$ $0.39 \mathrm{D}$ at four years after SMILE. No significant changes of SE occurred were also reported by Pedersen et al. and Blum et al. [13, 15]. These results demonstrate the predictability and stability of refractive outcomes after SMILE with 4 years of follow up. In terms of other refractive surgeries, several refractive results after LASIK [19-21] and photorefractive keratectomy (PRK) [22] showed a significant decline in SE over about ten years after the surgery, especially for high corrections and young patients. Therefore, it is necessary to investigate the stability of SMILE in the long term.

HOAs play an important role in retinal image quality. Similar to previous studies $[1,2,8,23]$, total HOAs, coma, spherical aberration and higher-order astigmatism increased postoperatively. Among these aberrations, postoperative coma was most affected and remained stable at all follow-up time points. The induced coma might be associated with decentration and special efforts should be made to minimize induced coma clinically [24]. In addition, no significant changes of aberrations were detected among the 1-month, 6-month, or 4-year follow-ups postoperatively. However, this is in contrast to a previous study using the Pentacam to analyze the anterior, posterior and total corneal aberrations, in which HOAs and spherical aberrations significantly decreased from 3 months to 3 years after SMILE [15]. In this study, we used the Hartmann-Shack WASCA aberrometer which measures the whole-eye wavefront aberrations. Different measurements might result in the different outcomes and the long-term changes of aberrations on SMILE still need further discussion.

Quality of life metrics assesses the changes in physical, functional, mental and social health in individuals. The comparison of quality of life between common treatments to myopia is helpful to evaluate the benefits of the refractive surgery. The QIRC questionnaire targets patients with refractive correction by spectacles, contact lenses and refractive surgery, and is rigorously developed using both conventional techniques and Rasch analysis 
Table 4 Differences in QIRC questionnaire items between surgery and spectacles groups

\begin{tabular}{|c|c|c|c|c|c|c|c|c|c|}
\hline \multirow[t]{2}{*}{ Variables } & \multicolumn{4}{|c|}{ Surgery group } & \multicolumn{4}{|c|}{ Spectacles group } & \multirow[t]{2}{*}{$P$} \\
\hline & Mean & SD & Medium & IQR & Mean & SD & Medium & IQR & \\
\hline 1. Total score & 45.71 & 2.61 & 45.36 & 43.73 to 47.51 & 39.96 & 3.56 & 39.42 & 37.11 to 41.65 & $<0.001$ \\
\hline $\begin{array}{l}\text { 2. How much difficulty do you have driving in glare } \\
\text { conditions? }\end{array}$ & 52.27 & 7.98 & 45.06 & 45.06 to 60.51 & 38.54 & 11.16 & 29.61 & 29.61 to 45.06 & $<0.001$ \\
\hline $\begin{array}{l}\text { 3. During the past month, how often have you experienced } \\
\text { your eyes feeling tired or strained? }\end{array}$ & 46.41 & 8.27 & 49.66 & 34.21 to 49.66 & 45.08 & 9.31 & 49.66 & 34.21 to 49.66 & 0.524 \\
\hline $\begin{array}{l}\text { 4. How much trouble is not being able to use off-the-shelf } \\
\text { (non prescription) sunglasses? }\end{array}$ & 47.77 & 11.87 & 56.71 & 41.26 to 56.71 & 34.97 & 9.73 & 41.26 & 25.81 to 41.26 & $<0.001$ \\
\hline $\begin{array}{l}\text { 5. How much trouble is having to think about your } \\
\text { spectacles or contact lenses or your eyes after refractive } \\
\text { surgery before doing things; eg, traveling, sport, going } \\
\text { swimming? }\end{array}$ & 58.93 & 5.79 & 61.37 & 61.37 to 61.37 & 41.91 & 12.44 & 45.92 & 30.47 to 45.92 & $<0.001$ \\
\hline $\begin{array}{l}\text { 6. How much trouble is not being able to see when you } \\
\text { wake up; eg, to go to the bathroom, look after a baby, } \\
\text { see alarm clock? }\end{array}$ & 56.88 & 5.79 & 59.32 & 59.32 to 59.32 & 44.44 & 9.94 & 43.87 & 43.87 to 43.87 & $<0.001$ \\
\hline $\begin{array}{l}\text { 7. How much trouble is not being able to see when you are } \\
\text { on the beach or swimming in the sea or pool, because } \\
\text { you do these activities without spectacles or contact } \\
\text { lenses? }\end{array}$ & 57.42 & 11.87 & 63.92 & 48.48 to 63.92 & 36.66 & 7.93 & 33.03 & 33.03 to 33.03 & $<0.001$ \\
\hline $\begin{array}{l}\text { 8. How much trouble is your spectacles or contact lenses } \\
\text { when you wear them when using a gym/ doing keep-fit } \\
\text { classes/circuit training, etc? }\end{array}$ & 32.40 & 11.93 & 24.27 & 24.27 to 39.72 & 29.21 & 8.51 & 24.27 & 24.27 to 39.72 & 0.351 \\
\hline $\begin{array}{l}\text { 9. How concerned are you about the initial and ongoing } \\
\text { cost to buy your current spectacles/ contact lenses/ } \\
\text { refractive surgery? }\end{array}$ & 58.92 & 7.66 & 64.61 & 49.16 to 64.61 & 49.16 & 12.73 & 49.16 & 33.71 to 64.61 & 0.004 \\
\hline $\begin{array}{l}\text { 10. How concerned are you about the cost of unscheduled } \\
\text { maintenance of your spectacles/ contact lenses/ } \\
\text { refractive surgery; eg, breakage, loss, new eye problems? }\end{array}$ & 47.61 & 13.87 & 45.18 & 29.73 to 60.62 & 38.88 & 12.19 & 29.73 & 29.73 to 45.18 & 0.015 \\
\hline $\begin{array}{l}\text { 11. How concerned are you about having to increasingly } \\
\text { rely on your spectacles or contact lenses since you } \\
\text { started to wear them? }\end{array}$ & 42.69 & 13.00 & 34.56 & 34.56 to 50.01 & 47.72 & 13.22 & 50.01 & 34.56 to 65.46 & 0.128 \\
\hline $\begin{array}{l}\text { 12. How concerned are you about your vision not being as } \\
\text { good as it could be? }\end{array}$ & 38.31 & 8.68 & 34.24 & 34.24 to 32.24 & 38.82 & 9.31 & 34.24 & 34.24 to 34.24 & 0.889 \\
\hline $\begin{array}{l}\text { How concerned are you about medical complications from } \\
\text { your choice of optical correction (spectacles, contact lenses } \\
\text { and/or refractive surgery)? }\end{array}$ & 34.28 & 10.57 & 28.59 & 28.59 to 44.04 & 38.89 & 11.23 & 44.04 & 28.59 to 44.04 & 0.084 \\
\hline $\begin{array}{l}\text { 13. How concerned are you about eye protection from } \\
\text { ultraviolet (UV) radiation? }\end{array}$ & 39.79 & 8.68 & 35.72 & 35.72 to 35.72 & 43.73 & 11.52 & 35.72 & 35.72 to 51.17 & 0.182 \\
\hline $\begin{array}{l}\text { 14. During the past month, how much of the time have you } \\
\text { felt that you have looked your best? }\end{array}$ & 39.75 & 12.36 & 45.52 & 28.25 to 45.52 & 38.11 & 12.97 & 28.25 & 28.25 to 45.52 & 0.536 \\
\hline $\begin{array}{l}\text { 15. During the past month, how much of the time have you } \\
\text { felt that you think others see you the way you would } \\
\text { like them to (eg, intelligent, sophisticated, successful, } \\
\text { cool, etc)? }\end{array}$ & 47.17 & 5.45 & 48.99 & 48.99 to 48.99 & 43.01 & 11.01 & 48.99 & 31.72 to 48.99 & 0.079 \\
\hline $\begin{array}{l}\text { 16. During the past month, how much of the time have you } \\
\text { felt complimented/flattered? }\end{array}$ & 51.51 & 11.34 & 54.55 & 37.28 to 54.55 & 48.50 & 12.01 & 54.55 & 37.28 to 54.55 & 0.304 \\
\hline $\begin{array}{l}\text { 17. During the past month, how much of the time have you } \\
\text { felt confident? }\end{array}$ & 44.87 & 9.63 & 42.67 & 42.67 to 57.94 & 39.10 & 11.98 & 42.67 & 25.40 to 42.67 & 0.063 \\
\hline $\begin{array}{l}\text { 18. During the past month, how much of the time have you } \\
\text { felt happy? }\end{array}$ & 46.04 & 7.75 & 39.61 & 39.61 to 54.88 & 38.60 & 10.51 & 39.61 & 39.61 to 39.61 & 0.008 \\
\hline $\begin{array}{l}\text { 19. During the past month, how much of the time have you } \\
\text { felt able to do the things you want to do? }\end{array}$ & 30.65 & 6.71 & 31.66 & 31.66 to 31.66 & 27.59 & 15.93 & 31.66 & 14.39 to 31.66 & 0.078 \\
\hline $\begin{array}{l}\text { 20. During the past month, how much of the time have you } \\
\text { felt eager to try new things? }\end{array}$ & 42.61 & 9.10 & 41.22 & 41.22 to 41.22 & 38.76 & 17.08 & 41.22 & 23.95 to 41.22 & 0.067 \\
\hline
\end{tabular}


[17]. The QIRC questionnaire has been used to measure differences between patients with correction by LASIK and other two modes of refractive correction [25, 26]. In this study, long-term quality of life outcomes on SMILE patients were studied. The total score of the QIRC questionnaire was significantly higher in the surgery group than the spectacles group. Compared to patients with refractive correction by spectacles, patients who underwent SMILE showed better refractive error-related quality of life and SMILE brings both economic benefits and convenience to individuals with moderate to high myopia.

A major weakness of this article is the relatively small sample size. It may limit the precision of the results. Further randomized and multi-centered studies with a larger sample size were of clinical significance.

\section{Conclusions}

In conclusion, SMILE provides a predictable and stable correction of moderate to high myopia in the long-term follow-up. Patients who underwent SMILE showed better quality of life compared to individuals who wore spectacles.

\section{Acknowledgements}

None.

\section{Funding}

Supported in part by the National Natural Science Foundation of China (Grant No. 81570879) and the Outstanding Academic Leaders Program of Shanghai Health System (Grant No. XBR2013098).

\section{Availability of data and materials}

Available upon request from the first author; Dr. Tian Han.

\section{Authors' contributions}

$\mathrm{TH}$ conceived of the study and drafted the manuscript. KZ collected the data and helped in drafting the manuscript. YJC collected the data and critically revised the manuscript. GY collected the data and critically revised the manuscript. LH conceived of the study and collected the data. XTZ conceived of the study, performed the surgery and revised the manuscript. All authors read and approved the final manuscript.

\section{Competing interests}

The authors declare that they have no competing interests.

\section{Consent for publication}

Not applicable.

\section{Ethics approval and consent to participate}

This study followed the tenets of the Declaration of Helsinki and was approved by the ethics committee of the Eye and ENT Hospital of Fudan University. Informed written consent was obtained from all participants.

\section{Author details}

${ }^{1}$ Department of Ophthalmology and Vision Science, Eye and ENT Hospital of Fudan University, No.19 Baoqing RoadXuhui District, Shanghai, China. ${ }^{2}$ Aier School of Ophthalmology, Central South University, Changsha, China. ${ }^{3}$ Department of Ophthalmology, UruTmqi Eye and ENT Hospital, No.387 Zhongshan Road, Urumqi, Xinjiang, China.

\section{References}

1. Shah R, Shah S, Sengupta S. Results of small incision lenticule extraction: All-in-one femtosecond laser refractive surgery. J Cataract Refract Surg. 2011;37:127-37.

2. Sekundo W, Kunert KS, Blum M. Small incision corneal refractive surgery using the small incision lenticule extraction (SMILE) procedure for the correction of myopia and myopic astigmatism: results of a 6 month prospective study. Br J Ophthalmol. 2011;95:335-9.

3. Kim JR, Kim BK, Mun SJ, Chung YT, Kim HS. One-year outcomes of small-incision lenticule extraction (SMILE): mild to moderate myopia vs. high myopia. BMC Ophthalmol. 2015;15:59.

4. $X u$ Y, Yang $Y$. Small-incision lenticule extraction for myopia: results of a 12-month prospective study. Optom Vis Sci. 2015;92:123-31.

5. Sekundo W, Gertnere J, Bertelmann T, Solomatin I. One-year refractive results, contrast sensitivity, high-order aberrations and complications after myopic small-incision lenticule extraction (ReLEx SMILE). Graefes Arch Clin Exp Ophthalmol. 2014;252:837-43.

6. Ang M, Mehta JS, Chan C, Htoon HM, Koh JC, Tan DT. Refractive lenticule extraction: transition and comparison of 3 surgical techniques. J Cataract Refract Surg. 2014;40:1415-24.

7. Reinstein DZ, Carp Gl, Archer TJ, Gobbe M. Outcomes of small incision lenticule extraction (SMILE) in low myopia. J Refract Surg. 2014;30:812-8.

8. Agca A, Demirok A, Cankaya KI, Yasa D, Demircan A, Yildirim Y, Ozkaya A, Yilmaz OF. Comparison of visual acuity and higher-order aberrations after femtosecond lenticule extraction and small-incision lenticule extraction. Cont Lens Anterior Eye. 2014;37:292-6.

9. Miao H, Tian M, Xu Y, Chen Y, Zhou X. Visual outcomes and optical quality after femtosecond laser small incision lenticule extraction: an 18-month prospective study. J Refract Surg. 2015;31:726-31.

10. Kamiya K, Shimizu K, Igarashi A, Kobashi H. Visual and refractive outcomes of small incision lenticule extraction for the correction of myopia: 1-year follow-up. BMJ Open. 2015;5, e008268.

11. Chansue E, Tanehsakdi M, Swasdibutra S, McAlinden C. Efficacy, predictability and safety of small incision lenticule extraction (SMILE). Eye Vis (Lond). 2015;2:14.

12. Ganesh S, Gupta R. Comparison of visual and refractive outcomes following femtosecond laser- assisted lasik with smile in patients with myopia or myopic astigmatism. J Refract Surg. 2014;30:590-6.

13. Blum M, Taubig K, Gruhn C, Sekundo W, Kunert KS. Five-year results of Small Incision Lenticule Extraction (ReLEx SMILE). Br J Ophthalmol. 2016;100:1192-5.

14. Blum M, Flach A, Kunert KS, Sekundo W. Five-year results of refractive lenticule extraction. J Cataract Refract Surg. 2014;40:1425-9.

15. Pedersen I B, Ivarsen A, Hjortdal J. Three-Year Results of Small Incision Lenticule Extraction for High Myopia: Refractive Outcomes and Aberrations. J Refract Surg. 2015;31:719-24.

16. Moshirfar M, McCaughey MV, Reinstein DZ, Shah R, Santiago-Caban L, Fenzl CR. Small-incision lenticule extraction. J Cataract Refract Surg. 2015:41:652-65.

17. Pesudovs K, Garamendi E, Elliott DB. The Quality of Life Impact of Refractive Correction (QIRC) Questionnaire: development and validation. Optom Vis Sci. 2004:81:769-77.

18. Xu Y, Yang $X, Y u Y$, Wang $Q$, Lü F. Application and evaluation of a quality of life scale for Chinese people with refractive correction. Chinese Ophthalmic Res. 2011;28:623-6.

19. Alio JL, Muftuoglu O, Ortiz D, Perez-Santonja JJ, Artola A, Ayala MJ, Garcia MJ, de Luna GC. Ten-year follow-up of laser in situ keratomileusis for myopia of up to -10 diopters. Am J Ophthalmol. 2008;145:46-54.

20. Zalentein WN, Tervo TM, Holopainen JM. Seven-year follow-up of LASIK for myopia. J Refract Surg. 2009;25:312-8.

21. Alio JL, Soria F, Abbouda A, Pena-Garcia P. Laser in situ keratomileusis for -6.00 to -18.00 diopters of myopia and up to -5.00 diopters of astigmatism: 15-year follow-up. J Cataract Refract Surg. 2015;41:33-40.

22. Alio JL, Muftuoglu O, Ortiz D, Artola A, Perez-Santonja JJ, de Luna GC, Abu-Mustafa SK, Garcia MJ. Ten-year follow-up of photorefractive keratectomy for myopia of less than -6 diopters. Am J Ophthalmol. 2008;145:29-36.

23. Tan DK, Tay WT, Chan C, Tan DT, Mehta JS. Postoperative ocular higherorder aberrations and contrast sensitivity: femtosecond lenticule extraction versus pseudo small-incision lenticule extraction. J Cataract Refract Surg. 2015;41:623-34

24. Li M, Zhao J, Miao H, Shen Y, Sun L, Tian M, Wadium E, Zhou X. Mild decentration measured by a Scheimpflug camera and its impact on visual 
quality following SMILE in the early learning curve. Invest Ophthalmol Vis Sci. 2014:55:3886-92

25. Meidani A, Tzavara C, Dimitrakaki C, Pesudovs K, Tountas Y. Femtosecond laser-assisted LASIK improves quality of life. J Refract Surg. 2012;28:319-26.

26. Garamendi E, Pesudovs K, Elliott DB. Changes in quality of life after laser in situ keratomileusis for myopia. J Cataract Refract Surg. 2005;31:1537-43.

Submit your next manuscript to BioMed Central and we will help you at every step:

- We accept pre-submission inquiries

- Our selector tool helps you to find the most relevant journal

- We provide round the clock customer support

- Convenient online submission

- Thorough peer review

- Inclusion in PubMed and all major indexing services

- Maximum visibility for your research

Submit your manuscript at www.biomedcentral.com/submit 